Old Dominion University ODU Digital Commons

Psychology Faculty Publications

Psychology

2019

\title{
Fighting For Time: Spillover and Crossover Effects of Long Work Hours Among Dual-Earner Couples
}

Xiaohong Xu

Old Dominion University, x3xu@odu.edu

Yisheng Peng

Peng Zhao

Richard Hayes

Old Dominion University, rhaye003@odu.edu

William P.Jimenez

Old Dominion University, wjimenez@odu.edu

Follow this and additional works at: https://digitalcommons.odu.edu/psychology_fac_pubs

Part of the Community Psychology Commons, Health Psychology Commons, Industrial and Organizational Psychology Commons, and the Performance Management Commons

\section{Repository Citation}

Xu, Xiaohong; Peng, Yisheng; Zhao, Peng; Hayes, Richard; and Jimenez, William P., "Fighting For Time: Spillover and Crossover Effects of Long Work Hours Among Dual-Earner Couples" (2019). Psychology Faculty Publications. 97.

https://digitalcommons.odu.edu/psychology_fac_pubs/97

\section{Original Publication Citation}

Xu, X., Peng, Y., Zhao, P., Hayes, R., \& Jimenez, W. P. (2019). Fighting for time: Spillover and crossover effects of long work hours among dual-earner couples. Stress and Health, 1-37. doi:10.1002/smi.2882

This Article is brought to you for free and open access by the Psychology at ODU Digital Commons. It has been accepted for inclusion in Psychology Faculty Publications by an authorized administrator of ODU Digital Commons. For more information, please contact digitalcommons@odu.edu. 
Xu Xiaohong (Orcid ID: 0000-0002-4087-1623)

Jimenez William (Orcid ID: 0000-0003-1141-4631)

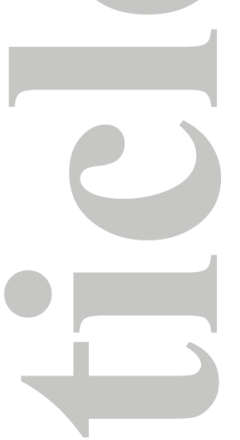

Fighting for time: Spillover and crossover effects of long work hours among dual-earner couples

Xiaohong Xu ${ }^{\mathrm{a}}$, Yisheng Peng ${ }^{\mathrm{b}}$, Peng Zhao ${ }^{\mathrm{c}}$, Richard Hayes ${ }^{\mathrm{a}}$, \& William P. Jimenez ${ }^{\mathrm{a}}$

a Department of Psychology, Old Dominion University, Norfolk, VA 23529

${ }^{\mathrm{b}}$ Department of Organizational Science and Communication, The George Washington

University, Washington, DC 20052

${ }^{c}$ Department of Management \& Entrepreneurship, Kelley School of Business, Indiana

University, Bloomington, IN 47405

Author's Note

Correspondence concerning this article can be addressed to Xiaohong (Violet) $\mathrm{Xu}$,

x3xu@ odu.edu; Tel: +1-757-683-4461; Department of Psychology, Old Dominion

University, Norfolk, VA 23529.

Conflict of Interest statement:

This article has been accepted for publication and undergone full peer review but has not been through the copyediting, typesetting, pagination and proofreading process which may lead to differences between this version and the Version of Record. Please cite this article as doi: $10.1002 / \mathrm{smi} .2882$ 
None of the authors has conflict of interest.

Data Accessibility statement:

The data reported in this manuscript were obtained from publicly available data, [the 500 Family Study,

https://www.icpsr.umich.edu/icpsrweb/instructors/studies/4549?sdaAvailable=true]. A

bibliography of journal articles, working papers, conference presentations, and dissertations using the 500 Family Study is available at

[https://www.icpsr.umich.edu/icpsrweb/ICPSR/studies/4549/publications]. The variables and relationships examined in the present article have not been examined in any previous or current articles, or to the best of my knowledge in any papers that will be under review soon. I acknowledge that the original collector of the data, ICPSR, and the relevant funding agency bear no responsibility for use of the data or for interpretations or inferences based upon such uses.

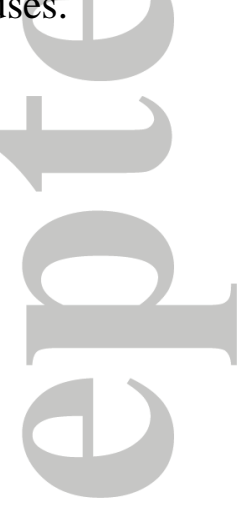

Drawing upon the spillover-crossover model, this study examined the extent to which one's work time demands spilled over to the family domain, and crossed over to his or her spouse, utilizing data of 365 dual-earner couples from the 500 Family Study. The results of the distinguishable actor-partner interdependence model indicated that there was gender symmetry in the spillover processes such that the effects of work hours were identical between men and women. Further, although there was more bi-directional crossover between 
partners within couples, we observed some unidirectional crossover from husbands to wives. Specifically, husbands only increased their contribution to domestic work in response to wives' work fatigue, whereas wives increased their contribution to domestic work in response to husbands' work fatigue and high workloads. Finally, husbands' housework hours negatively related to wives' marital satisfaction and positively related to wives' depression, whereas wives' housework hours negatively related to husbands' marital satisfaction and depression. These findings have practical implications for improving the work-family balance, health, and well-being of dual-earner couples.

Keywords: spillover; crossover; work hours; domestic work hours; distinguishable actor-partner interdependence model

Fighting for time: Spillover and crossover effects of long work hours among dual-earner couples

Working long hours is prevalent in the United States and many other countries. Globally, about $22 \%$ of employees work more than 48 hours per week (Bannai \& Tamakoshi, 2014). Working long hours has been an issue to employees, organizations, and societies. For instance, long work hours have been demonstrated to have detrimental effects on various desired employee outcomes, such as decreased performance, impaired health, and well-being (e.g., Bannai \& Tamakoshi, 2014). Previous research has greatly added to our understanding of the negative consequences of long work hours (e.g., Byron, 2005; Ford, Heinen, \& Langkamer, 2007). However, several gaps remain in the literature.

First, previous research has predominantly examined work hours and household labor hours independently (Bianchi \& Raley, 2005). Scholars have argued that examining the time spent on work and family roles together will help disentangle the complexities of the workfamily interface (Ganster, Rosen, \& Fisher, 2018). Work hours can be viewed as an objective 
measure of work demands (Ganster \& Rosen, 2013), whereas housework hours can be viewed as an objective measure of home demands (Shelton \& John, 1996). Both work and family are "greedy institutions" (Coser, 1974) that demand resources (e.g., time and energy) as much as possible from individuals (Greenhaus \& Beutell, 1985). Time-based work-family conflict occurs when time devoted to one domain makes it difficult to meet demands from the other domain (Greenhaus \& Beutell, 1985). Therefore, the time spent on work and housework together influences the level of work-family conflict and the subsequent strains.

Second, empirical studies have revealed inconsistent findings regarding the moderating role of gender in the context of time-based work-family conflict (Ganster et al., 2018). Employed women may be more vulnerable to work time demands, as they are managing two roles (i.e., income earner and care provider; Gutek, Searle, \& Klepa, 1991). However, some researchers argued that the detrimental effects of long work hours are stronger for men (Ng \& Feldman, 2008; Wharton \& Blair-Loy, 2006). Interestingly, empirical studies have revealed mixed findings regarding gender differences in the impact of work hours (e.g., Ng \& Feldman, 2008). Correspondingly, researchers have called for "a deeper exploration of gender effects" (Ganster et al., 2018, p. 35) on the impact of work hours.

Finally, previous research on work hours focuses on the individual, isolating the individual from the family context (e.g., Clinton, Conway, \& Sturges, 2017). However, the detrimental impact of work hours may depend on spousal influences, as time is not only an individual resource, but also a family resource. One's spouse could influence his or her time allocation. For instance, employees with partners who are unemployed may be able to spend more time on work, as their partners may be responsible for a larger share of household chores. On the other hand, one's work demands could spill over from work to home and influence his or her spouse. Thus, there are mutual influences between partners within 
couples, suggesting a need for examining the broader family system by treating the couple as the unit of analysis to understand the work-family interface (Hammer, Bauer, \& Grandey, 2003; Hammer, Neal, Newsom, Brockwood, \& Colton, 2005; Westman, 2002, 2006). Correspondingly, researchers have called for studies that unravel the complexities of the work-family spillover and crossover effects by examining the spousal influence (Keizer \& Schenk, 2012).

To address these gaps, we use the spillover-crossover model (SCM; Bakker \& Demerouti, 2012) as the theoretical framework to examine the spillover and crossover of work time demands, with a sample of 365 dual-earner, heterosexual couples. We also examined the gender differences in these spillover and crossover processes. The global workforce is rife with dual-earner couples (Jacobs \& Gerson, 2004). For instance, about 70\% of couples in the United States are dual-earning (Jacobs \& Gerson, 2004). Dual-earner couples may be especially vulnerable to work and family demands (Aryee, Srinivas, \& Tan, 2005). We believe that it is of practical importance to examine how dual-earner couples handle work and family demands.

We aim to contribute to the literature in three meaningful ways. First, scholars have called for examining the effects of work hours as a job demand while controlling for the effects of housework hours (e.g., Ganster et al., 2018). To the best of our knowledge, our study is the first study that responds to this call by examining the effects of work hours on multiple stress-related outcomes (i.e., work fatigue, work-family conflict, marital satisfaction, and depression) while ruling out the confounding effects of housework hours as a family demand. Second, Westman (2006) suggested that, in order to fully investigate the crossover processes, researchers should simultaneously examine three phases within the same study: (1) the relationship between the individual's stress and strain, (2) the linkage between work and family (i.e., spillover) for the individual, and (3) the crossover of the individual's stress to his 
or her spouse. To date, no studies have modeled all three phases when exploring the crossover of work hours and housework hours as work and family demands and their consequent strains (i.e., work fatigue, work-family conflict, marital satisfaction, and depression) with the dual-earner couple as the unit of analysis. This represents a surprising gap as accumulated evidence has supported that some of these variables are related to one another (e.g., Amstad, Meier, Fasel, Elfering, \& Semmer, 2011; Ford et al., 2007). For instance, empirical studies, including meta-analytic studies, have suggested that work-family conflict mediates the relationship between marital dissatisfaction and depression (e.g., Amstad et al., 2011; Ford et al., 2007). Previous research has largely examined the crossover of marital satisfaction, depression, or work-family conflict independently. Neglecting these intercorrelations among the variables across the three phases may contribute to the mixed findings concerning the gender differences in the directionality of the crossover processes of stress and strains (e.g., marital satisfaction and depression) between husbands and wives (Westman, 2002, 2006). By modeling these phases (i.e., a chain of multiple variables) simultaneously, we are more accurately representing the actual world or environment that our dual-earner couples are functioning in while accounting for the covariance among the variables. For instance, Saxbe, Repetti, and Graesch (2011) found that the crossover of time spent on housework on the cortisol level disappeared, when marital satisfaction was controlled. Third, Westman $(2002,2006)$ proposed that the mixed findings regarding the gender differences in the directionality of the crossover processes may be partially due to other variables that are related to gender, such as gender role expectations and employment status (i.e., full-time vs. part-time). Our study is the first study that examines the gender differences in the directionality of the crossover of work hours and housework hours within dual-earner couples, while controlling for the effects of gender role expectations regarding the "breadwinners" and the employment status of husbands and wives. Additionally, we 
control for the number of jobs, socioeconomic status (i.e., education and income), and the number of children in the family. By ruling out these confounding variables, we are able to provide a more accurate and complete picture of the spillover and crossover processes and more robust tests of the gender differences in the directionality of the crossover of work hours as a job demand and housework hours as a home demand on multiple stress-related outcomes within dual-earner couples (Westman, 2002, 2006).

\section{Literature Review and Hypothesis Development}

The SCM (Bakker \& Demerouti, 2013) suggests that there are two critical processes through which experiences in one domain (e.g., work) spill over to another domain (e.g., family) and cross over from one person to another person. Spillover refers to an intraindividual transmission of stress or strains where one's experiences in one domain are transferred into another domain and affect his or her experiences in that domain (Bolger,

DeLongis, Kessler, \& Wethington, 1989). Crossover reflects an inter-individual transmission where an individual's stress or strains in one domain influences the levels of stress and strains experienced by another individual (Bolger et al., 1989; Westman, 2001). That is, crossover focuses on the transmission of stress and strains across individuals. For instance, one's long work hours or burnout could influence his or her partner's work hours and/or burnout.

\section{Spillover}

Accumulated evidence has suggested that gender role expectations have remained unchanged in the past three decades (Bianchi \& Milkie, 2010; Lachance-Grzela \& Bouchard, 2010). Women are still expected to be "homemakers," whereas men are expected to be "breadwinners" (Bianchi \& Milkie, 2010). Researchers have argued that job demands, such as long work hours, may be more demanding to employed women than men due to gender inequalities in domestic work (Gutek et al., 1991). Wives are under the societal pressure to manage the bulk of domestic work, regardless of their employment status (Bianchi \& Milkie, 
2010). Juggling family and work roles may further deplete women's resources, resulting in their vulnerability to work time demands (Bianchi \& Milkie, 2010). In contrast, husbands are shielded from the pressure of managing roles of careers and providers, because they are relatively free of family demands (Gutek et al., 1991). Conservation of resources theory proposes that individuals are motivated to obtain, retain, and protect resources (e.g., time and energy) and that they experience strains when they perceive threats of resource loss or experience actual resource loss (Hobfoll, 2001). Drawing upon conservation of resources theory, managing both work and family roles can lead to role conflict and strains due to time loss and energy drain (Hobfoll, 2001). Therefore, long work hours may have a greater impact on women than on men. One counter argument is that men are more affected by long work hours, as a career is central to men's identities (Cinamon \& Rich, 2002; Ng \& Feldman, 2008), and men are more directly affected by substantial job demands (Wharton \& Blair-Loy, 2006), which add further burden to men and consequently result in their vulnerability to work time demands.

Interestingly, empirical studies have revealed mixed findings regarding the gender differences in the effects of work hours (Ganster et al., 2018). We speculate that these mixed findings are due to neglecting the role of domestic workload. Researchers have acknowledged the importance of exploring workloads in both paid and domestic work to disentangle the gender differences in the effects of work hours (Ganster et al., 2018). The gendered division of employment and domestic work reinforces normative gender role expectations, which might influence the extent to which men and women are vulnerable to work and home demands (Eby, Casper, Lockwood, Bordeaux, \& Brinley, 2005). That is, a gendered workplace and a gendered family might intersect to create gender differences in the vulnerability to work time demands. Role stress theory, which has been widely used in workfamily research (Rantanen, Kinnunen, Mauno, \& Tillemann, 2011), suggests that work and 
home demands together affect the levels of role conflict and role overload women and men experience in dual-earner families. For example, employed women may experience role overload if there is an imbalance in the allocation of domestic work, whereas employed men may experience role conflict when they are doing housework, which is incongruent with the gender role expectations that women are responsible for the household chores and men are the "breadwinners." The effects of home time demands should be accounted for in order to accurately detect gender differences in the effects of work hours. Indeed, some studies have emphasized the importance of considering the role of domestic workload when studying gender differences. For instance, Roxburgh (2004) demonstrated that housework time explained why employed women experienced higher levels of depression than employed men. Given the conflicting arguments and findings, we developed the following question:

Research Question: Are there gender differences in the effects of work hours on various outcomes while controlling for housework hours?

\section{Crossover}

Researchers have long recognized the importance of studying the work-family interface using the couple rather than the individual as the unit of analysis (Greenhaus \& Powell, 2012; Westman, 2002, 2006; Westman \& Etzion, 2005). However, previous research on work hours has predominantly focused on the individual as the unit of analysis, as opposed to the couple (e.g., Clinton et al., 2017). Examining the effects of work time demands with couples as the unit of analysis allows us to scrutinize the spousal influence, or the crossover between partners within couples (Westman, 2001, 2002, 2006). As mentioned previously, crossover refers to a dyadic, inter-individual transmission of stresses and/or strains from one person to another (Westman, 2001; Westman \& Vinokur, 1998).

Decision process theory of work and family proposes that individuals make decisions regarding the time allocation into work and family roles, which precede and follow work- 
family conflict (Poelmans, 2005; Edwards \& Rothbard, 2000). When one member of the couple acts on his or her decisions, he or she will not only consider his or her personal needs, but also the spouse's needs due to one's tendency to attend to the spouse and to reciprocate (Poelmans, 2005). For instance, when one's spouse is experiencing high job demands (e.g., long work hours) and high levels of strain (e.g., work fatigue), he or she is likely to invest more resources into handling family demands, such as doing more household labor. Thus, we expect that spouse's long work hours and work fatigue will lead to an increase in one's domestic work hours. Further, these individuals are likely to experience increased workfamily conflict, as they are responsible for an increased share of household duties, which will contribute to overload and energy depletion and increased tension associated with managing work and family roles.

Hypothesis 1: Employees whose partners (a) work long hours and (b) are experiencing work fatigue will increase hours for household chores.

Hypothesis 2: Employees whose partners (a) work long hours and (b) are experiencing work fatigue will experience more work-family conflict.

Although the evidence concerning the gender differences in crossover is inconclusive, there is more evidence supporting unidirectional crossover from husbands to wives than vice versa (Westman, 2002, 2006; Westman, Brough, \& Kalliath, 2009). For instance, Westman (2002) concluded that "the crossover process is unidirectional, or at least stronger from husbands to wives, who are more frequently the recipients of the husbands' stress and strain" (p. 145). Westman (2002) further summarized three major findings or arguments that provide support for the unidirectional crossover from husbands to wives. First, wives experience higher levels of demands than husbands and consequently are not resilient to husbands' stress and strains. Second, wives are more empathetic than husbands or are able to "feel into" husbands' stress and strains. Third, wives are expected to be care and support providers and 
consequently are more vulnerable to husbands' stress and strains. In other words, women are expected to focus on family over work, and they are more attuned to external factors that influence the family functioning and the well-being of the family members (Bianchi \& Milkie, 2010; Westman, 2002). Therefore, women will be more likely to change their behaviors to meet family members' needs. In contrast, men are more concerned with their work role and less affected by family responsibilities, as they place higher priority on work responsibilities (Voydanoff, 1988). Indeed, research has suggested that wives are more sensitive to husbands' emotions, demands, and strains (Johnson \& Jackson, 1998; Larson \& Almeida, 1999). Under the normative pressure to be ideal homemakers, women are more sensitive to their husbands' work demands and strains. Thus, husbands' work hours and work fatigue will have larger impact on wives than vice versa.

Hypothesis 3: Husbands' (a) work hours and (b) work fatigue will have larger impact on wives' outcomes than vice versa.

Gender role expectations also suggest that family functioning and housework (e.g., cleaning the home) are considered reflections of a woman's competence as a wife rather than a man's competence as a husband. The long hours that her husband spends on household chores may suggest that a woman does not fulfill her responsibilities as a wife; failure to fulfill such responsibilities may impair a woman's marital satisfaction, health, and wellbeing. Indeed, research has suggested that women are self-critical about their performance in fulfilling family responsibilities (Biernat \& Wortman, 1991). Thus, we expect that husbands' housework hours will reduce wives' marital satisfaction and increase wives' depression. In contrast, as domestic work is widely considered "women's work," husbands may perceive their wives' contributions to housework as normative. Gender role expectations suggest that women's reduced contribution to domestic work might be considered out-of-role behaviorperhaps explaining why women's participation in the labor force market has not translated 
into an egalitarian allocation of household labor (Lachance-Grzela \& Bouchard, 2010). Indeed, a body of recent research suggests that women continue to undertake a larger share of household chores to maintain the family (e.g., Erickson, 2005; Pinto \& Coltrane 2009). It is expected that women's reduced contribution to domestic work might be considered out-ofrole behavior, and this role incongruity may reduce husbands' marital satisfaction and increase husbands' depression. In sum, although we expect that there are bidirectional crossover effects of housework hours, we hypothesize that the crossover of husbands' housework hours on wives' marital satisfaction and depression will be different from the crossover of wives' housework hours on husbands' marital satisfaction and depression. Hypothesis 4: Husbands' housework hours will be (a) negatively related to wives' marital satisfaction and (b) positively related to wives'depression.

Hypothesis 5: Wives' housework hours will be (a) positively related to husbands' marital satisfaction and (b) negatively related to husbands' depression.

\section{Method}

\section{Participants and Procedures}

We tested our hypotheses with data from the 500 Family Study ${ }^{1}$ conducted between 1998 and 2000 in the United States (Schneider \& Waite, 2008). Participants were recruited through phone, mail, newspaper advertisements, and posts. Eight urban and suburban communities in the United States were sampled to represent varying degrees of urbanization, socioeconomic status, and labor force composition. The sample of the 500 Family Study represents one of the most time-pressured segments of the population (Schneider \& Waite, 2008). Thus, it is well suited to use this sample to test our hypotheses. Further, researchers have continued to use the data from the 500 Family Study to examine contemporary work and family issues (e.g., French et al., 2016; Frost, Hoyt, Chung, \& Adam, 2015; Matjasko, \&

\footnotetext{
${ }^{1}$ Interested readers can refer to https://www.icpsr.umich.edu/icpsrweb/instructors/studies/4549 for more details regarding the 500 Family Study and research that has utilized the dataset.
} 
Feldman, 2006). Also, it is not uncommon for scholars (e.g., ten Brummelhuis, Haar, \& van der Lippe, 2010; Trombello, Schoebi, \& Bradbury, 2011) to use archival datasets that are decades old to explore contemporary work and family issues as gender role expectations and work and family issues have remained unchanged in the past several decades.

The original sample consisted of 512 dual-earner families. Researchers met with participants in their homes. All participants were assigned identification numbers to be linked to survey data without names on any survey materials. Respondents were asked to keep their responses to themselves to avoid influencing other family members' responses. Husbands and wives completed different versions of surveys. Respondents received no incentives beyond a report regarding the findings from the 500 Family Study (Schneider \& Waite, 2008). Three hundred and sixty-five couples had complete information regarding our study variables. Thus, our analyses were limited to these 365 dual-earning, heterosexual couples. The majority of the participants were White and non-Hispanic (88.8\%), Asian or Pacific Islander (2.0\%), Hispanic (2.7\%), Black (5.2\%), Asian/Pacific Islander and White (0.4\%), Hispanic and White $(0.3 \%)$, Black and White $(0.1 \%)$, and White and American Indian/Alaskan $(0.6 \%)$.

The average age of husbands was $46.22(S D=6.53)$, and the average age of wives was 44.61 $(S D=5.84)$.

\section{Measures}

Work Hours. Work hours was measured by one item (“Approximately how many hours do you spend working for your main job in a typical week?"). Participants were asked to respond on a 7-point scale $(1-15,16-25,26-37,38-45,46-50,51-60$ hours, and more than 60 hours).

Housework Hours. Respondents were asked how many hours per week they personally spend on household chores, such as shopping for the household, taking the kids to 
and from activities, cooking, etc. Participants were asked to respond on a 7-point scale $(0,1$ 2, 3-5, 6-10, 11-15, 16-20 hours, and more than 20 hours).

Work Fatigue. Work fatigue was measured by three items (e.g., "How often do you finish your workday feeling physically exhausted?") with a 5-point scale ranging from 0 (never) to 4 (always). The validity of this measure has been supported by previous studies (e.g., French et al., 2016).

Work-family Conflict. Work-family conflict was measured with one-item, "How often do you feel that work roles and family roles conflict?" with a 4-point scale ranging from 0 (never) to 4 (very often). Single-item measures of work-family conflict have been frequently used in large-scale social surveys (e.g., Health and Retirement Study) and provide useful information with acceptable psychometric properties (Fisher, Matthews, \& Gibbons, 2016).

Marital Satisfaction. Relationship satisfaction was assessed with the 10-item ENRICH Marital Satisfaction Scale (Fowers \& Olson, 1993). Respondents were asked to respond on a 5-point scale ranging from 1 (strongly disagree) to 5 (strongly agree).

Depression. Depression was measured with the 20-item Center for Epidemiological Studies Depression Scale (Radloff, 1977). Respondents were asked to indicate how often they experienced a number of feelings during the past week on a 4-point scale ranging from 0 (rarely or none of the time) to 3 (most or all of the time).

Control Variable. We controlled for the number of children, socioeconomic status (indicated by education and income, see Duncan, Daly, McDonough, \& Williams, 2002), the number of jobs, employment status (i.e., full-time versus part-time), as well as the gender role expectations regarding the "breadwinner" using one item (i.e., who do you feel should provide the majority of the income in your family?"). 


\section{Data Analysis}

We used the distinguishable actor-partner interdependence model (APIM; Fitzpatrick, Gareau, Lafontaine, \& Gaudreau, 2016) to examine the impact of one's causal variable on his or her own outcome variables (i.e., actor effects) and on his or her partner's outcome variables (i.e., partner effects). The actor effect of the husband $(\mathrm{X} 1 \rightarrow \mathrm{Y} 1)$ refers to the effect of the predictor variable (X1) of the husband on his own outcome variable (Y1), whereas the partner effect $(\mathrm{X} 1 \rightarrow \mathrm{Y} 2)$ refers to the effect of the predictor variable $(\mathrm{X} 1)$ of the husband on the outcome variable (Y2) of his wife (see Figure 1). The common practices of APIM analyses are to test the fit of more parsimonious models. These parsimonious models include models that constrain actor and/or partner effect estimates to be equal. For instance, we compare models constraining actor effects (i.e., Figure 1, A1 = A2) and partner effects (i.e., Figure $1, \mathrm{P} 12=\mathrm{P} 21$ ) separately (i.e., $\mathrm{A} 1=\mathrm{A} 2 \neq \mathrm{P} 12=\mathrm{P} 21$ ), to a model constraining all these four effects to be equal (i.e., $\mathrm{A} 1=\mathrm{A} 2=\mathrm{P} 12=\mathrm{P} 21$ ). The purpose of these practices is to test significant differences in actor and partner effects between husbands and wives (Gonzalez \& Griffin, 2001). Because we used the distinguishable APIM (Fitzpatrick et al., 2016; Peugh, DiLillo, \& Panuzio, 2013), the dyadic pattern for each relationship between two variables can be the same or different between husbands and wives. For instance, the relationship between A and B could be actor-only for husbands but couple-oriented (i.e., both actor and partner effects) for wives.

As the present study involves relationships among multiple variables (Figure 2), we used structural equation modeling to analyze our APIM (Peugh et al., 2013) and conducted equal constraint tests sequentially starting from the most distal predictor to its most immediate outcome (i.e., work hours $\rightarrow$ work fatigue). For instance, the results of the APIM analyses indicated that there was an actor-only effect of work hours on work fatigue for both husbands and wives (thus, partner effects were not considered for the work hours $\rightarrow$ work 
fatigue relationship for both husbands and wives) and that the actor effect was equal between husbands and wives. These constraints were retained in all subsequent models that test the equality of actor and partner effects for all other relationships (e.g., work fatigue $\rightarrow$ housework hours, marital satisfaction $\rightarrow$ depression). We analyzed 34 models $^{2}$ for testing these equal constraints (see the supplemental material for details). For simplification, we only reported the final model (Table 2 and Figure 2). This final model fit the data very well $\left[\chi^{2}(110)=115.43, p>.05, \mathrm{RMSEA}=0.01, \mathrm{CFI}=0.99, \mathrm{SRMR}=0.03\right]$, and the chi-square difference tests supported that this model fit the data better compared to all other alterative models. It should be noted that the results of the model with control variables were almost identical to the model without control variables, except for the relationship between housework hours and depression (although the estimated value was close, this estimate became non-significant). Following Becker's (2005) suggestions, we reported the results with control variables (see Table 2 and Figure 2).<smiles>C1CC[In]CC1</smiles>

\section{Results}

Descriptive statistics and correlations are presented in Table 1. Again, both partner and actor effects were tested for both husbands' and wives' outcomes in our model.

Following the most common practice, and for the sake of simplification, we only presented the significant paths (see Table 2 and Figure 2). Actor effects of work hours on housework hours $(B=-0.06, p<.01)$ and work fatigue $(B=0.13, p<.001)$ were equal between husbands and wives (see Table 2). Work hours did not have direct actor effects on work-family conflict, marital satisfaction, and depression for both husbands and wives. Regarding our Research Question, these results suggested that there were no gender differences in the actor effects of work hours.

\footnotetext{
${ }^{2}$ Specific estimates for all these alternative models are available upon request. Estimates for the significant paths in these models are quite similar to the estimates of the final model presented in Figure 2.
} 
There was a positive association between husbands' work hours and wives' housework hours $(B=0.06, p<.001)$ but no significant relationship between wives' work hours and husbands' housework hours (see Table 2). That is, there was a partner effect of husbands'work hours on wives' housework hours but no significant partner effect of wives' work hours on husbands' housework hours. Thus, Hypothesis 1a was partially supported. Further, there was a partner effect of work fatigue on housework hours for both husbands ( $B$ $=0.09, p<.001)$ and wives $(B=0.09, p<.001)$, supporting Hypothesis $1 \mathrm{~b}$.

Partner's work hours was not directly related to one's work-family conflict. Thus, Hypothesis 2a was not supported. There was a partner effect of work fatigue on husbands' ( $B$ $=0.09, p<.05)$ and wives' $(B=0.09, p<.05)$ work-family conflict, supporting Hypothesis $2 \mathrm{~b}$. We also observed equal actor effects of work fatigue on work-family conflict between husbands and wives $(B=0.41, p<.001)$.

Husbands' work hours was significantly related to wives' housework hours $(B=0.06$, $p<.001$ ), but wives' work hours was not significantly related to husbands' housework hours, suggesting husbands' work hours had a larger impact on wives' housework hours than vice versa. Similarly, husbands' work fatigue was negatively related to wives' marital satisfaction $(B=-0.13, p<.001)$, whereas wives' work fatigue was not significantly related to husbands' marital satisfaction. We did not observe stronger partner effects of work hours and work fatigue on wives' work-family conflict and depression compared to husbands' work-family conflict and depression. That is, the effects of husbands' work hours and work fatigue $(B=$ $0.09, p<.05)$ on wives' work-family conflict were equal to the effects of wives' work hours and work fatigue $(B=0.09, p<.05)$ on husbands' work-family conflict, partially supporting Hypothesis 3.

Husbands' housework hours was negatively related to wives' marital satisfaction $(B=$ $-0.16, p<.001)$ but was not significantly related to wives' depression $(B=0.04, p<.05)$. 
Thus, Hypothesis 4 was partially supported. Interestingly, wives' housework hours was negatively related to husbands' marital satisfaction $(B=-0.16, p<.001)$ but not depression $(B$ $=-0.04, p>.001)$, partially supporting Hypothesis 5 .

\section{Discussion}

There are more dual-earner families compared to other family forms in the United States (Casper \& Bianchi, 2002; Jacobs \& Gerson, 2004). Dual-earner couples have adopted lifestyles in which both partners have jobs outside the home and share the "second shift" at home (Hochschild, 1989), and they are especially susceptible to work and home demands (Aryee et al., 2005). In response to calls for more research examining the work-family interface with the couple as the unit of analysis (Keizer \& Schenk, 2012; Westman, 2001, 2002, 2006), we adopted the SCM (Bakker \& Demerouti, 2012) to examine the spillover and crossover of work time demands and the resulting strains, using a sample of 365 dual-earner, heterosexual couples. We found that there were transmissions of stressors (i.e., work hours and housework hours) and strains (i.e., work fatigue, work-family conflict, marital dissatisfaction, and depression) between the work and family domains (i.e., intra-individual transmission) and between partners within couples (i.e., inter-individual transmission).

\section{Implications for Research}

Because one's work demands and home demands together contribute to the extent of work-family conflict, a complete picture of how an individual balances work and home responsibilities can be obtained by examining how work and home demands simultaneously impact one's work-family conflict and subsequent strains (e.g., depression). However, previous research has largely focused on the independent effects of work hours and household labor hours (e.g., Ford et al., 2007), ignoring the combination effects of work hours and housework hours (Ganster et al., 2018). In response to calls for disentangling the gender effect on the work hours-strain relationships (Ganster et al., 2018), we examined 
whether the effects of work hours on work fatigue, work-family conflict, marital satisfaction, and depression differed between men and women, while controlling for the effects of workloads in domestic work (i.e., housework hours). After taking into account the time spent on domestic work, we found no significant gender differences in the effects of work hours. In other words, husbands and wives were equally susceptible to work time demands.

Work time demands not only transmit from the work domain to the family domain within an individual, but also transmit from an individual to his or her partner. However, the majority of the research on work time demands has focused on individuals, isolating the influence from their spouses (e.g., Clinton et al., 2017). To address this issue, we examined the spillover and crossover of work time demands by using the couple as the unit of analysis and emphasized the influence of the broader social context of an individual—specifically, the spousal influence (Greenhaus \& Powell, 2012; Westman, 2002, 2006). We found that one's work time demands and the consequent strains could influence the levels of stress and strains experienced by his or her spouse (i.e., partner effect) and that there was gender symmetry and asymmetry in these interpersonal influences or crossover between partners within couples, suggesting complex relationships between stresses and strains at the couple level (cf. Westman, 2002).

Our findings of the gender differences in crossover (i.e., gender asymmetry) provide some indirect evidence for the proposition that the gendered division of employment and domestic work reinforces normative gender role expectations that define women as "homemakers" and men as "breadwinners" (Eby et al., 2005). For instance, husbands did not increase their contribution to housework when their wives worked long hours, whereas wives increased their housework hours in response to husbands' long work hours (Bolger et al., 1989). Consistent with the gender role expectation that domestic work is "women's work," wives' housework hours contributed to wives' work-family conflict, whereas husbands' 
housework hours did not contribute to husbands' work-family conflict. Further, we found that husbands' work fatigue was negatively related to wives' marital satisfaction, whereas wives' work fatigue was not related to husbands' marital satisfaction. Perhaps because men are considered "breadwinners" for the family and their paid work is viewed as evidence of their masculinity (Townsend, 2002), wives may interpret their husbands' work fatigue as evidence of incompetence, which in turn decreases wives' marital satisfaction. Consistent with Westman's (2002) observation, our findings suggest that wives are more sensitive to husbands' stresses and strains, resulting in more unidirectional crossover from husbands to wives than vice versa (Johnson \& Jackson, 1998; Westman 2001).

Although our findings suggest that gender played a role in the crossover processes, there was more gender symmetry than asymmetry in the crossover processes. For example, we found that the effects of husbands' work fatigue on wives' housework hours and workfamily conflict were the same as the effects of wives' work fatigue on husbands' housework hours and work-family conflict. The coexistence of gender symmetry and asymmetry in the crossover processes in this study is consistent with the mixed findings regarding the gender differences in the crossover processes (Westman, 2002, 2006; Westman et al., 2004; Westman \& Etzion, 2005). Our study contributes to the literature by demonstrating that gender role expectations regarding the breadwinner, employment status, and socioeconomic status do not contribute to the observed gender differences in the directionality of the crossover process. Our study and previous studies together suggest that when and why gender asymmetry or gender symmetry in the crossover processes occurs still remain open questions in the crossover literature (cf. Bakker, Westman, \& van Emmerik, 2009). A mixed-method approach might be appropriate to address these conflicting findings, as it not only allows us to quantify gender differences, but also helps us better understand when and why gender 
differences in the crossover processes occur using qualitative data (i.e., comments and illustrations/examples from the respondents).

\section{Practical Implications}

Our findings suggest that work fatigue due to long work hours is more influential in increasing work-family conflict than the sheer amount of time spent on work. To effectively reduce work-family conflict (and other stress-related outcomes) due to long work hours, dualearner couples may focus on managing and reducing work fatigue through multiple strategies, such as consuming healthy snacks, hydrating regularly, taking frequent breaks at work (if organizational policy permits), and exercising regularly so as to improve sleep quality and work recovery (Sonnentag, Binnewies, \& Mojza, 2008). Our findings also highlight the crossover of work and home time demands and the resulting strains (e.g., workfamily conflict, marital satisfaction, and depression) between partners within couples. As such, dual-earner couples may consider outsourcing household chores in order to reduce the strains due to time restrictions imposed by the management of one's work roles and family roles (ten Brummelhuis et al., 2010).

\section{Strength, Limitations, and Future Directions}

One strength of our study is that we simultaneously examined time demands from both work and family domains to disentangle the gender effects on the work hours-strain relationships (Ganster et al., 2018). Another strength is our use of couple data, which adds the dyadic level of analysis and enables us to examine both intra-individual and inter-individual transmissions of stresses and strains in the work-family interface. Further, the dual-earner couples from the 500 Family Study represent a heterogeneous sample in terms of occupations and industries, covering varying degrees of urbanization, socioeconomic status, and labor force composition (Schneider \& Waite, 2008), which may help reduce the concern about external validity that previous studies using homogenous samples may suffer from (e.g., 
Saxbe et al., 2011; Trombello, Schoebi, \& Bradbury, 2011). However, we acknowledge several limitations that open areas for future research.

First, the cross-sectional design of our study does not allow for causal inference. Wang and Repetti (2004) found that one's job distress and depressive symptoms predicted social support from the spouse. It is possible that one's depression level may influence his or her time allocation to work and housework activities (i.e., reverse causal relationships). However, our hypotheses were based on relevant theories, and our findings were consistent with these theoretical predictions. Further, previous longitudinal studies have provided evidence regarding the causal direction of the relationships examined in the present study (e.g., Trinkoff, Geiger-Brown, Lipscomb, \& Lang, 2006). We encourage researchers to use longitudinal designs with repeated measurements, such as diary studies or experience sampling methods, to replicate the present findings.

Second, our measures of work hours and housework hours may limit the true variance in actual work hours and housework hours. However, the use of Likert-point scales to measure work hours is not uncommon in the literature (e.g., Saxbe et al., 2011; Vieira, Matias, Lopez, \& Matos, 2016). We call for researchers to use better measures of work hours and housework hours to test our hypotheses.

Third, although the 500 Family Study data cover a relatively recent period (i.e., 19982000), there is a lag between the data collection and today's labor market. However, there is ample evidence supporting the rigidity of gender beliefs and the strength of gender-typed behaviors over time (Bianchi \& Milkie, 2010; Ridgeway 1997). The 500 Family Study data are still meaningful and appropriate for the research questions under investigation. For instance, the analyses of the 500 Family Study data revealed that husbands had significantly longer work hours and fewer housework hours than wives; these findings are consistent with recent research using data collected more recently (e.g., Saxbe et al., 2011). Further, research 
has suggested that work and family issues have remained unchanged in the past three decades. For instance, Galinsky, Aumann, and Bond (2009) observed that "the level of worklife conflict experienced by employed mothers in dual-earner couples has not changed significantly over the past three decades" (p. 19). Although scholars have continued to use the 500 Family Study data to explore contemporary work and family issues (e.g., French et al., 2016; Frost et al., 2015; Matjasko \& Feldman, 2006), research is needed to collect new data to replicate our findings.

Finally, our sample focused on dual-earner, heterosexual couples, and thus our findings might not be generalizable to unmarried couples, homosexual couples, or singleparent families. However, the use of a homogenous sample (i.e., heterosexual couples) controls for potentially confounding variables and thus reduces the likelihood that our findings result from uncontrolled differences (McClenahan, Giles, \& Mallett, 2007). Also, the family system, very often, includes not only the couple, but also other family members (e.g., children and/or elder dependents). Exclusively focusing on spouses ignores the potential impact other family members can have on how an individual allocates his or her resources (e.g., time) at work and at home. However, we controlled for the number of children, and our measure of housework hours includes time spent taking care of children; doing so has allowed us to partially address the aforementioned issue. We encourage researchers to examine our findings with other populations and explore the demands from other family members. Perhaps the most appropriate level of analysis for exploring work and family issues is to treat the family (neither the couple nor the individual) as the unit of analysis, which includes all members into one single model.

\section{Conclusions}

In response to scholars' call for research to examine work hours and household labor hours simultaneously (e.g., Ganster et al., 2018), we conducted the first empirical study to 
explore the effects of work hours on multiple stress-related outcomes while controlling for the effects of housework hours, with a sample of 356 dual-earner couples. We found that working husbands and working wives were equally susceptible to long work hours in terms of work fatigue, work-family conflict, marital satisfaction, and depression, while controlling for the effect of home time demands. Scholars have speculated that the conflicting findings regarding the gender differences in the directionality of crossover may be due to the confounding effects of the variables that are related to gender, such as gender role attitudes and employment status (Westman, 2002, 2006). We contribute to the literature by ruling out the confounding effects of employment status, the number of jobs, gender role expectations regarding the breadwinner, and socioeconomic status and demonstrating that wives were more attuned to husbands' stresses and strains, resulting in more unidirectional crossover from husbands to wives than vice versa.

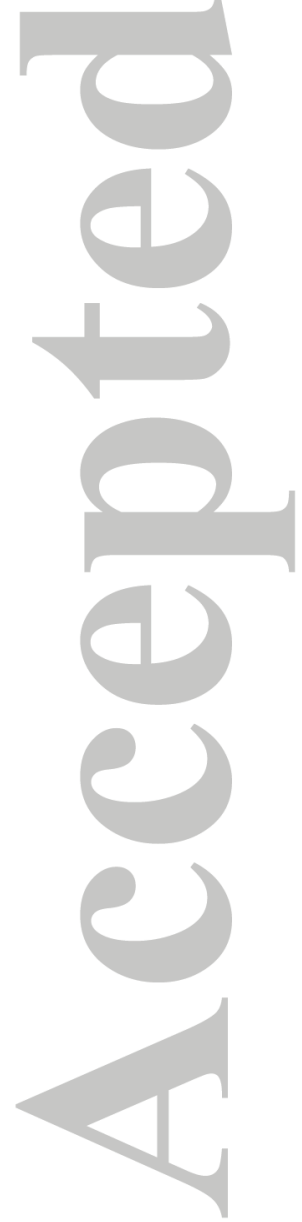




\section{References}

Amstad, F. T., Meier, L. L., Fasel, U., Elfering, A., \& Semmer, N. K. (2011). A metaanalysis of work-family conflict and various outcomes with a special emphasis on cross-domain versus matching-domain relations. Journal of Occupational Health Psychology, 16, 151-169.

Aryee, S., Srinivas, E. S., \& Tan, H. H. (2005). Rhythms of life: Antecedents and outcomes of work-family balance in employed parents. Journal of Applied Psychology, 90, 132146.

Bakker, A. B., \& Demerouti, E. (2012). The Spillover-Crossover model. In J. Grzywacz, \& E. Demerouti (Eds.), New frontiers in work and family research. Hove: Psychology Press.

Bakker, A. B., Westman, M., \& Hetty van Emmerik, I. J. (2009). Advancements in crossover theory. Journal of Managerial Psychology, 24, 206-219.

Becker, T. E. (2005). Potential problems in the statistical control of variables in organizational research: A qualitative analysis with recommendations. Organizational Research Methods, 8, 274-289.

Bianchi, S. M., \& Milkie, M. A. (2010). Work and family research in the first decade of the 21st century. Journal of Marriage and Family, 72, 705-725.

Bianchi, S. M., \& Raley, S. B. (2005). Time allocation in families. In S. M. Bianchi, L. M. Casper, \& R. B. King (Eds.), Work, family health, and well-being (pp. 21 -42). Philadelphia: Erlbaum.

Biernat, M., \& Wortman, C. B. (1991). Sharing of home responsibilities between professionally employed women and their husbands. Journal of Personality and Social Psychology, 60, 844-860. 
Bannai, A., \& Tamakoshi, A. (2014). The association between long working hours and health: a systematic review of epidemiological evidence. Scandinavian Journal of Work, Environment \& Health, 40, 5-18.

Bolger, N., DeLongis, A., Kessler, R. C., \& Wethington, E. (1989). The contagion of stress across multiple roles. Journal of Marriage and the Family, 51, 175-183.

Byron, K. (2005). A meta-analytic review of work-family conflict and its antecedents. Journal of Vocational Behavior, 67, 169-198.

Casper, L.M., \& Bianchi, S.M., (2002). Change and continuity in the American family. Sage Publications, Thousand Oaks, CA.

Cinamon, R. G., \& Rich, Y. (2002). Gender differences in the importance of work and family roles: Implications for work-family conflict. Sex Roles, 47, 531-541.

Clinton, M. E., Conway, N., \& Sturges, J. (2017). "It's tough hanging-up a call”: The relationships between calling and work hours, psychological detachment, sleep quality, and morning vigor. Journal of Occupational Health Psychology, 22, 28-39.

Coser, L. (1974). Greedy institutions: Patterns of undivided commitment. New York: Free Press.

Duncan, G. J., Daly, M. C., McDonough, P., \& Williams, D. R. (2002). Optimal indicators of socioeconomic status for health research. American Journal of Public Health, 92, $1151-1157$.

Eby, L. T., Casper, W. J., Lockwood, A., Bordeaux, C., \& Brinley, A. (2005). Work and family research in IO/OB: Content analysis and review of the literature (1980-2002). Journal of Vocational Behavior, 66, 124-197.

Edwards, J. R., \& Rothbard, N. P. (2000). Mechanisms linking work and family: Clarifying the relationship between work and family constructs. Academy of Management Review, 25, 178-199. 
Erickson, R. J. (2005). Why emotion work matters: Sex, gender, and the division of household labor. Journal of Marriage and Family, 67, 337-351.

Fisher, G. G., Matthews, R. A., \& Gibbons, A. M. (2016). Developing and investigating the use of single-item measures in organizational research. Journal of Occupational Health Psychology, 21, 3-23.

Fitzpatrick, J., Gareau, A., Lafontaine, M.-F., \& Gaudreau, P. (2016) How to Use the ActorPartner Interdependence Model (APIM) To Estimate Different Dyadic Patterns in MPLUS: A Step-by-Step Tutorial. The Quantitative Methods for Psychology, 12, 7486.

Fowers, B. J., \& Olson, D. H. (1993). ENRICH Marital Satisfaction Scale: A brief research and clinical tool. Journal of Family Psychology, 7, 176.

Ford, M. T., Heinen, B. A., \& Langkamer, K. L. (2007). Work and family satisfaction and conflict: A meta-analysis of cross-domain relations. Journal of Applied Psychology, $92,57-80$.

French, K. A., Butts, M. M., \& Allen, T. D. (2016). Parent work conditions and adolescent core self-evaluations: Examining the effects of work resource drain and parent gender. Journal of Business and Psychology, 31, 553-568.

Frost, A., Hoyt, L. T., Chung, A. L., \& Adam, E. K. (2015). Daily life with depressive symptoms: Gender differences in adolescents' everyday emotional experiences. Journal of Adolescence, 43, 132-141.

Galinsky, Aumann, \& Bond (2009). Times Are Changing: Gender and Generation at Work and at Home. Families and Work Institute.

Ganster, D. C., \& Rosen, C. C. (2013). Work stress and employee health: A multidisciplinary review. Journal of Management, 39, 1085-1122. 
Ganster, D. C., Rosen, C. C., \& Fisher, G. G. (2018). Long working hours and well-being: What we know, what we do not know, and what we need to know. Journal of Business and Psychology, 33, 25-39.

Gonzalez, R., \& Griffin, D. (2001). Testing parameters in structural equation modeling: Every" one" matters. Psychological Methods, 6, 258.

Greenhaus, J. H., \& Beutell, N. J. (1985). Sources of conflict between work and family roles. Academy of Management Review, 10, 76-88.

Greenhaus, J. H., \& Powell, G. N. (2012). The family-relatedness of work decisions: A framework and agenda for theory and research. Journal of Vocational Behavior, 80, 246-255.

Gutek, B. A., Searle, S., \& Klepa, L. (1991). Rational versus gender role explanations for work-family conflict. Journal of Applied Psychology, 76, 560-568.

Hammer, L. B., Bauer, T. N., \& Grandey, A. A. (2003). Work-family conflict and workrelated withdrawal behaviors. Journal of Business and Psychology, 17, 419-436.

Hammer, L. B., Neal, M. B., Newsom, J. T., Brockwood, K. J., \& Colton, C. L. (2005). A longitudinal study of the effects of dual-earner couples' utilization of family-friendly workplace supports on work and family outcomes. Journal of Applied Psychology, 90, 799-810.

Hochschild, A. (1989). The second shift: Working parents and the revolution at home.

Hobfoll, S. E. (2001). The influence of culture, community, and the nested-self in the stress process: advancing conservation of resources theory. Applied psychology, 50, 337421.

Jacobs, J. A., \& Gerson, K. (2004). The time divide: Work, family, and gender inequality. Cambridge, MA:_Harvard University Press. 
Johnson, A., \& Jackson, P. (1998). A longitudinal investigation into the experience of male managers who have reentered the workforce after redundancy, and their families.

Proceedings of the International Work Psychology Conference, Sheffield, July.

Keizer, R., \& Schenk, N. (2012). Becoming a parent and relationship satisfaction: A longitudinal dyadic perspective. Journal of Marriage and Family, 74, 759-773.

Lachance-Grzela, M., \& Bouchard, G. (2010). Why do women do the lion's share of housework? A decade of research. Sex Roles, 63, 767-780.

Larson, R.W., \& Almeida, D. M. (1999). Emotional transmission in the daily lives of families: A new paradigm for studying family process. Journal of Marriage and the Family, 61, 5-20.

McClenahan, C. A., Giles, M. L., \& Mallett, J. (2007). The importance of context specificity in work stress research: A test of the Demand-Control-Support model in academics. Work \& Stress, 21, 85-95.

Newkirk, K., Perry-Jenkins, M., \& Sayer, A. G. (2017). Division of household and childcare labor and relationship conflict among low-income new parents. Sex Roles, 76, 319333.

Ng, T. W., \& Feldman, D. C. (2008). Long work hours: A social identity perspective on meta - analysis data. Journal of Organizational Behavior, 29, 853-880.

Peugh, J. L., DiLillo, D., \& Panuzio, J. (2013). Analyzing mixed-dyadic data using structural equation models. Structural Equation Modeling: A Multidisciplinary Journal, 20, 314-337.

Pinto, K. M., \& Coltrane, S. (2009). Divisions of labor in Mexican origin and Anglo families: Structure and culture. Sex Roles, 60, 482-495.

Poelmans, S. A. Y. (2005). The Decision Process Theory of Work and Family. In E. E. Kossek \& S. J. Lambert (Eds.), LEA's organization and management series. Work and 
life integration: Organizational, cultural, and individual perspectives (pp. 263-285).

Mahwah, NJ, US: Lawrence Erlbaum Associates Publishers.

Radloff, L. S. (1977). The CES-D scale: A self-report depression scale for research in the general population. Applied Psychological Measurement, 1, 385-401.

Rantanen, J., Kinnunen, U., Mauno, S., \& Tillemann, K. (2011). Introducing theoretical approaches to work-life balance and testing a new typology among professionals. In

S. Kaiser, M. Ringlstetter, D. Eikhof, \& M. P. Cunha (Eds.), Creating balance?! (pp. 27-46). Springer: Berlin/Heidelberg, Germany.

Ridgeway, C. L. (1997). Interaction and the conservation of gender inequality: Considering employment. American Sociological Review, 62, 218-235.

Roxburgh, S. (2004). “There just aren't enough hours in the day': The mental health consequences of time pressure. Journal of Health and Social Behavior, 45, 115-131.

Saxbe, D. E., Repetti, R. L., \& Graesch, A. P. (2011). Time spent in housework and leisure: Links with parents' physiological recovery from work. Journal of Family Psychology, $25,271-281$.

Schneider, B., \& Waite, L. J. (2008). The 500 Family Study [1998-2000: United States]: Ann Arbor, MI: Inter-university Consortium for Political and Social Research [distributor]. Shelton, B. A., \& John, D. (1996). The division of household labor. Annual Review of Sociology, 22, 299-322.

Sonnentag, S., Binnewies, C., \& Mojza, E. J. (2008). "Did you have a nice evening?" A daylevel study on recovery experiences, sleep, and affect. Journal of Applied Psychology, 93, 674-684.

ten Brummelhuis, L. L., Haar, J. M., \& van der Lippe, T. (2010). Crossover of distress due to work and family demands in dual-earner couples: A dyadic analysis. Work \& Stress, 24, 324-341. 
Townsend, N. (2002). The packaged deal: Marriage, work, and fatherhood in men's lives. Philadelphia: Temple University Press.

Trinkoff, A. M., Le, R., Geiger-Brown, J., Lipscomb, J., \& Lang, G. (2006). Longitudinal relationship of work hours, mandatory overtime, and on - call to musculoskeletal problems in nurses. American Journal of Industrial Medicine, 49, 964-971.

Trombello, J. M., Schoebi, D., \& Bradbury, T. N. (2011). Relationship functioning moderates the association between depressive symptoms and life stressors. Journal of Family Psychology, 25, 58-67.

Vieira, J. M., Matias, M., Lopez, F. G., \& Matos, P. M. (2016). Relationships between workfamily dynamics and parenting experiences: A dyadic analysis of dual-earner couples. Work \& Stress, 30, 243-261.

Voydanoff, P. (1988). Work role characteristics, family structure demands, and work/family conflict. Journal of Marriage and the Family, 50, 749-761.

Wang, S.-W., \& Repetti, R. L. (2014). Psychological well-being and job stress predict marital support interactions: A naturalistic observational study of dual-earner couples in their homes. Journal of Personality and Social Psychology, 107, 864-878.

Westman, M. (2001). Stress and strain crossover. Human Relations, 54, 717-751.

Westman, M. (2002). Gender asymmetry in crossover research. In D. Nelson, \& R. Burke (Eds.), Gender, work stress and health (pp. 129-150). Washington DC: American Psychological Association.

Westman, M. (2006). Crossover of stress and strain in the work-family context. In F. Jones, R. Burke, \& M. Westman (Eds.), Work-life balance: A psychological perspective (pp.163-184). New York: Psychology Press. 
Westman, M., Brough, P., \& Kalliath, T. (2009). Expert commentary on work-life balance and crossover of emotions and experiences: Theoretical and practice advancements. Journal of Organizational Behavior, 30, 587-595.

Westman, M., \& Etzion, D. L. (2005). The crossover of work-family conflict from one spouse to the other. Journal of Applied Social Psychology, 35, 1936-1957.

Westman, M., \& Vinokur, A. D. (1998). Unraveling the relationship of distress levels within couples: Common stressors, empathic reactions, or crossover via social interaction?. Human Relations, 51, 137-156.

Westman, M., Vinokur, A. D., Hamilton, V. L., \& Roziner, I. (2004). Crossover of marital dissatisfaction during military downsizing among Russian army officers and their spouses. Journal of Applied Psychology, 89, 769-779.

Wharton, A. S., \& Blair-Loy, M. (2006). Long work hours and family life: A cross-national study of employees' concerns. Journal of Family Issues, 27, 415-436.

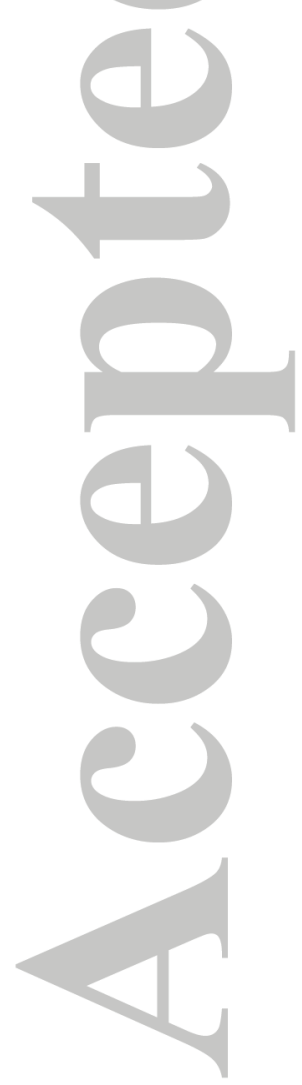


Table 1 Descriptive Statistics and Correlations among the Study Variables

\begin{tabular}{|c|c|c|c|c|c|c|c|c|c|c|c|c|}
\hline Variables & 1 & 2 & 3 & 4 & 5 & 6 & 7 & 8 & 9 & 10 & 11 & 12 \\
\hline \multicolumn{13}{|l|}{ 1. Work hours (W) } \\
\hline 2. Work hours (H) & -.04 & & & & & & & & & & & \\
\hline $\begin{array}{l}\text { 3. Housework } \\
\text { hours }(W)\end{array}$ & $-.19 *$ & .12 & & & & & & & & & & \\
\hline $\begin{array}{l}\text { 4. Housework } \\
\text { hours (H) }\end{array}$ & $.11 *$ & $-.16^{*}$ & .05 & & & & & & & & & \\
\hline $\begin{array}{l}\text { 6. Work fatigue } \\
\text { (H) }\end{array}$ & .01 & $.17^{*}$ & $.11^{*}$ & .01 & -.04 & $(.72)$ & & & & & & \\
\hline $\begin{array}{l}\text { 7. Work-family } \\
\text { conflict }(W)\end{array}$ & -.02 & .02 & .04 & .07 & $.24^{*}$ & .06 & & & & & & \\
\hline $\begin{array}{l}\text { 8. Work-family } \\
\text { conflict }(\mathbf{H})\end{array}$ & .02 & .03 & .11 & $.11 *$ & .07 & $.35^{*}$ & $.14^{*}$ & & & & & \\
\hline 11. Depression (W) & .06 & -.05 & .10 & $.19 *$ & $.29 *$ & .00 & $.23^{*}$ & .04 & $-.33^{*}$ & $-.21 *$ & $(.89)$ & \\
\hline 12. Depression (H) & -.02 & -.02 & .00 & .04 & -.02 & $.39 *$ & .01 & $.17^{*}$ & $-.31^{*}$ & $-.40^{*}$ & .04 & $(.89)$ \\
\hline Mean & 3.40 & 4.87 & 1.68 & 1.24 & 1.92 & 1.89 & 2.31 & 2.27 & 3.62 & 3.65 & 0.39 & 0.42 \\
\hline$S D$ & 1.49 & 1.16 & 0.51 & 0.45 & 0.66 & 0.62 & 0.85 & 0.71 & 0.76 & 0.70 & 0.35 & 0.36 \\
\hline
\end{tabular}

Note. $* p<.05 . N=365$ couples. Cronbach's alpha is on the diagonal.

$\mathrm{H}$ : Husbands' variables; W: Wives' variables. 
Table 2 Summary of direct actor and partner effects of the study variables

\begin{tabular}{|c|c|c|c|c|}
\hline Direct relationships & Actor-only & Partner-only & Couple-oriented & Contrast \\
\hline \multicolumn{5}{|c|}{ Husbands' variables as outcomes } \\
\hline work hours $\rightarrow$ work fatigue & $0.13 *$ & & & \\
\hline work hours $\rightarrow$ housework hours & $-0.06^{*}$ & & & \\
\hline work fatigue $\rightarrow$ housework hours & & $0.09 *$ & & \\
\hline work fatigue $\rightarrow$ work-family conflict & & & Actor: $0.41^{*}$ & \\
\hline & & & Partner: $0.09 *$ & \\
\hline housework hours $\rightarrow$ marital satisfaction & & & Equal effects:-0.16* & \\
\hline work fatigue $\rightarrow$ marital satisfaction & $-0.13^{*}$ & & & \\
\hline work-family conflict $\rightarrow$ marital satisfaction & & & Equal effects:-0.09* & \\
\hline housework hours $\rightarrow$ depression & & $-0.04^{b}$ & & \\
\hline work fatigue $\rightarrow$ depression & $0.16^{*}$ & & & \\
\hline marital satisfaction $\rightarrow$ depression & $-0.15^{*}$ & & & \\
\hline
\end{tabular}

\section{Wives' variables as outcomes}

work hours $\rightarrow$ work fatigue

$0.13^{*}$

work hours $\rightarrow$ housework hours ${ }^{\mathrm{a}}$

work fatigue $\rightarrow$ housework hours

work fatigue $\rightarrow$ work-family conflict

\section{$0.09 *$}

Actor: $0.41^{*}$

Partner: $0.09^{*}$ 
housework hours $\rightarrow$ marital satisfaction

work fatigue $\rightarrow$ marital satisfaction ${ }^{\mathrm{a}}$

work-family conflict $\rightarrow$ marital satisfaction

housework hours $\rightarrow$ depression $^{\mathrm{a}}$

work fatigue $\rightarrow$ depression

marital satisfaction $\rightarrow$ depression
Equal effects:-0.16*

Equal effects:-0.13*

Equal effects:-0.09*

Note. ${ }^{*} p<.05 . \quad N=365$ couples. ${ }^{a} \mathbf{P}$

Partner effect: There is only a partner effect. Couple-oriented pattern: The direction of the actor effect is the same to that of the partner effect.

Contrast pattern: The direction of the actor effect is opposite to the effect of the partner effect. ${ }^{\mathrm{b}}$ The effect became non-significant when including control variables. The number of children, socioeconomic (i.e., education and income), employment status (full-time versus part-time), gender role attitude and the number of jobs were controlled.

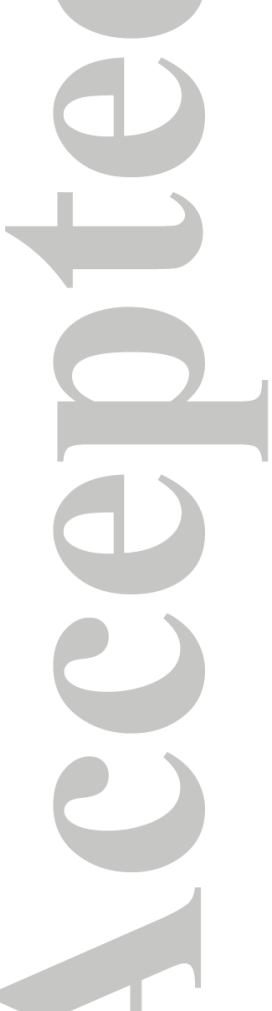


Figure 1

The actor-partner interdependence model (APIM) for distinguished dyads (i.e., couples)

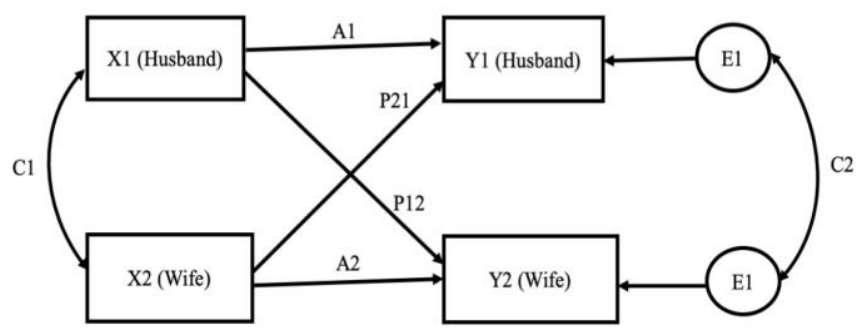

Note.

Al - the actor effect of husbands' variable (X1) on husbands' outcome variable (Y1)

A2 - the actor effect of wives' variable (X2) on wives' outcome variable (Y2).

P12 - the partner effect of husbands' variable (X1) on wives' outcome variable (Y2).

$\mathrm{P} 21$ - the partner effect of wives' variable (X2) on husbands' outcome variable (Y1)

Dyadic pattern should be tested for each member of the dyads in the distinguishable APIM. For instance, for a relationship between two variables, there might be an actor-only effect for husbands, whereas there might be both actor and partner effects for wives.

Actor-only pattern: There is only an actor effect.

Partner effect: There is only a partner effect.

Couple-oriented pattern: The direction of the actor effect is the same to that of the partner effect.

Contrast pattern: The direction of the actor effect is opposite to the effect of the partner effect.

Figure 1. The actor-partner interdependence model (APIM) for distinguished dyads (i.e., couples).

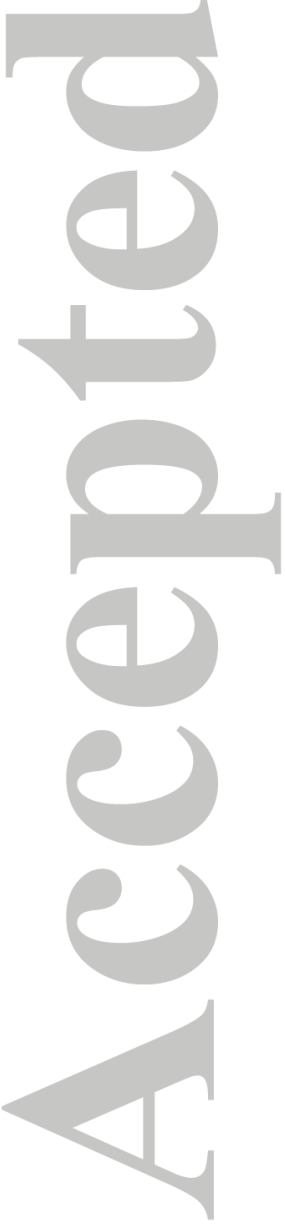


Figure 2

The final APIM.

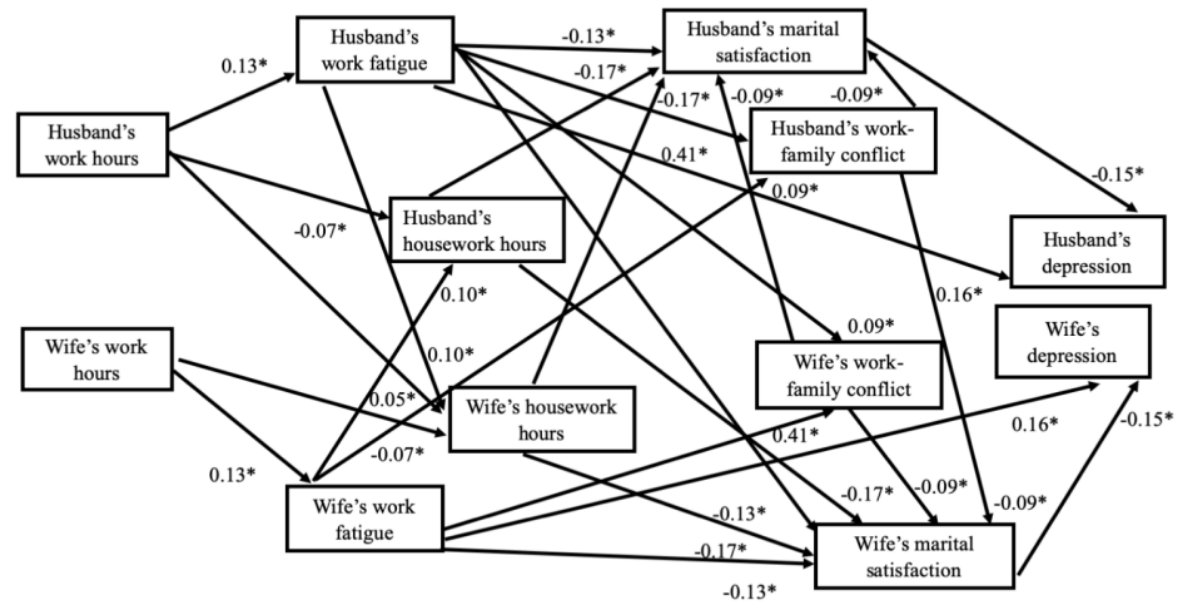

Note. Bidirectional crossover was tested for each relationship. Non-significant paths were dropped from the final APIM. ${ }^{*} p<.05$.

Figure 2. The final actor-partner interdependence model. 